\title{
Ethics in studies on children and environmental health
}

\author{
D F Merlo, L E Knudsen, K Matusiewicz, L Niebrój, K H Vähäkangas
}

J Med Ethics 2007;33:408-413. doi: 10.1136/jme.2006.016212

Children, because of age-related reasons, are a vulnerable population, and protecting their health is a social, scientific and emotional priority. The increased susceptibility of children and fetuses to environmental (including genotoxic) agents has been widely discussed by the scientific community. Children may experience different levels of chemical exposure than adults, and their sensitivity to chemical toxicities may be increased or decreased in comparison with adults. Such considerations also apply to unborn (fetal exposure) and newborn (neonatal exposure) children. Therefore, research on children is necessary in both clinical and environmental fields, to provide age-specific relevant data regarding the efficacy and safety of medical treatments, and regarding the assessment of risk from unintended environmental exposure. In this context, the stakeholders are many, including children and their parents, physicians and public health researchers, and the society as a whole, with its ethical, regulatory, administrative and political components. The important ethical issues are information of participants and consent to participate. Follow-up and protection of data (samples and information derived from samples) should be discussed in the context ofbiobanks, where children obtain individual rights when they become adults. It is important to realise that there are highly variable practices within European countries, which may have, in the past, led to differences in practical aspects of research in children. A number of recommendations are provided for research with children and environmental health. Environmental research with children should be scientifically justified, with sound research questions and valid study protocols of sufficient statistical power, ensuring the autonomy of the child and his/her family at the time of the study and later in life, if data and samples are used for follow-up studies. When children are enrolled, we recommend a consent dyad, including (1) parental (or legal guardian) informed consent and (2) the child's assent and/or informed consent from older minors. For evaluation of the studies including children, a paediatrician should always be involved in the research ethics committee.

See end of article for authors' affiliations

Correspondence to: Dr D F Merlo, Epidemiology and Biostatistics, Istituto Nazionale per la Ricerca sul Cancro, Largo Rosanna Benzi 10, 16132 Genova, Italy; franco.merlo@istge.it

Received 20 February 2006 Revised 21 August 2006 Accepted 29 August 2006
$\mathrm{R}$ ecognition of crimes, abuses, injustice and discrimination perpetrated in the name of medical research led to the formulation of basic ethical principles some 50 years ago. ${ }^{1}$ Such principles concern medical experiments on human beings aimed at gathering results meant for the good of the society and that are unprocurable by other methods or means of study. According to these principles, individuals participating in research have the right to know about the consequences of research to their life and health, and the scientists carrying out the research must conform to the ethics of the medical profession to satisfy moral, ethical and legal requirements. Since the Nuremberg trial, voluntary consent from human subjects has been regarded as an absolutely essential element in human experimentation. ${ }^{1}$ Research on individuals may concern diseased (patients) or healthy people (general population). Research on the former populations includes therapeutic research (eg, randomised clinical trials) aimed at investigating treatments that might benefit the sick, whereas research on the latter includes non-therapeutic research (eg, environmental health studies) aimed at acquiring knowledge that usually is of no immediate benefit to the study participants. Implementation of the basic ethical principles can result in more detailed ethical guidelines for therapeutic and non-therapeutic research..$^{2-7}$ Most of the guidelines promote the following four basic principles of biomedical ethics: autonomy, beneficence, non-maleficence and justice. ${ }^{8}$

Autonomy is related to respect for the person, and is commonly understood as his/her right to know or not to know, and as his/her freedom in making decisions (to participate in or not to participate in, or withdraw from, the research). For persons with diminished capacity of selfdetermination (including children who, due to age-related physical, mental and psychological development, may not be fully capable of understanding the research issues, benefits and risks), the right to be protected is in line with this principle. It requires a written informed consent, which again can only be based on adequate and relevant information to potential study participants. Indeed, only truly comprehended information can guarantee a free-will decision after understanding all research implications (intentionality and voluntariness). ${ }^{2}$ The principles of beneficence and non-maleficence imply the obligation of maximising possible benefits, protecting participants from potential/predictable harm and securing their well-being. Justice addresses the issue of fairness of the distribution of research benefits and risks. Only reasons strictly related to research objectives, and not their easy availability or other population-specific characteristics (eg, ethnic minorities, the socioeconomically less advantaged, gender, etc), should define the criteria for selection of participants In environmental as well as therapeutic research, justice is directly linked to the validity of the study, and to the possibility of extrapolating research findings from the study sample to the target population.

Abbreviation: RECs, research ethics committees 


\section{SUSCEPTIBILITY AND VULNERABILITY OF CHILDREN}

A possibly increased susceptibility of children and fetuses to environmental (including genotoxic) agents has been widely discussed by the scientific community. ${ }^{10-14}$ Children may experience different levels of exposure to environmental agents than adults, and their sensitivity to chemical toxicities may be different. ${ }^{10-14}$ Such considerations also apply to unborn (fetal exposure) and newborn (neonatal exposure) children. ${ }^{13}$ These are issues that require sound scientific answers that often can be achieved only by conducting studies in children rather than in surrogate populations. Therefore, research with and on children is necessary within both clinical and environmental fields, to provide age-specific, relevant data regarding the efficacy and safety of medical treatments, and regarding assessment of risk from unintended environmental exposure. In this context, the stakeholders are many, including children and their parents, physicians and public health researchers, and the society as a whole, with its ethical, regulatory, administrative and political components.

The health of children depends largely on the environment they live in. Environment-related issues, ethically difficult to accept, include tobacco advertising in developing countries targeted at children, exposing unborn and small children to second-hand smoke, and exposing other children to occupational toxic agents. Also important is the environmental pollution from industries in developing countries, which cannot operate the same way in more strictly regulated countries. Future generations will also be interested in the nuclear waste storage, water and ground pollution by agricultural chemicals, the gene modification of (farm) plants, as well as worldwide mass production of various nanoparticles. On the basis of the ethical requirement for justice, it is thus important to improve environmental conditions in all countries, including the developing countries, for the benefit of future generations. Research on environmental exposures and their related effects can hopefully address and justify public health-oriented political decisions.

Children are also vulnerable in general, and, in conditions where people suffer, children suffer the most. Currently, one of the most burning issues in biomedical research is how the money is spent. The balance between the costs in Western societies and those of the developing countries does not seem right as long as children starve. Research-related questions are: which diseases and conditions should be emphasised when developing healthcare strategies, and what standard of healthcare should be provided during the study for volunteers who come from less developed countries? ${ }^{15}$ Such balancing has already happened in some cases-for instance, in the case of companies developing and selling AIDS medication. However, this did not happen internationally, owing to the "good will" of companies that did not raise outcry about the injustice being perpetrated on poor nations not being able to pay Western prices. The expression of public opinions and the freedom to do it is ethically extremely important.

\section{AUTONOMY AND DEVELOPMENTAL STAGE OF CHILDREN}

Planning research on children requires that special attention is devoted to their capabilities and development. The ability of making independent decisions (understanding, competence) is strictly connected to the process of thinking. Given the variation in development during infanthood, childhood and adolescence, understanding and determining objectively the child's capacity to understand complex research issues is a big challenge to researchers. To be able to answer the question "at what age are children able to make decisions consciously and independently?" requires good knowledge of the development of abstract thinking. In early childhood, thinking does not constitute a separate and independent cognitive activity, but is merely subject to practical acts (ie, concrete actions taken by the child). Four age-related developmentally different phases can be identified. From a few months after birth up to $2 \frac{1 / 2}{2}$ years of age, motor-sensorial intelligence is predominant. From $2 \frac{1}{2}$ to 6 years of age, a child thinks by means of images and focuses upon one directly perceived aspect of a given situation (preoperational intelligence). Concrete notions start appearing at the age of 6-11 years, resulting in what is called orientation in reality. Later in life, activities become intentional and planned. ${ }^{16-18}$ At the age of 12 years, abstract thinking appears, which is built up by the age of 15 years. It enables a child to give independent opinions and to perceive a situation multidimensionally. ${ }^{19-21}$

With younger children (aged $<15$ years) who are not able to fully understand all aspects of the research, the principle of respecting their way of understanding should be taken into due consideration. If a child perceives the research situation as negative, resulting in negative emotions, this should be respected and taken into account. This approach is based on the relational paradigm of stress, a transactional conception of stress and how to cope with it, attributed to Lazarus and coworkers. ${ }^{22-26}$ Cognitive appraisal is the key concept in the theory by Lazarus, and it is based on determining the relationship between requirements, restrictions and resources of the environment and personal features of an individual. The essence of a person's perception of stress is based on the relationship between human beings and the environment, which is evaluated by the person as aggravating or exceeding his or her resources and threatening his or her prosperity. ${ }^{26} 27$

Although for the above-reported reasons, autonomy is not within the reach of small children, the opinions of older children are generally asked and taken into account in the medical decisions. ${ }^{28}$ However, modern biomedical research, including molecular and genetic epidemiology with its complex designs, is difficult to comprehend even for an adult. The fact that it is not simple to formulate the information contained in such documents in an understandable form for the target groups makes the whole issue of autonomy and informed consent the more important. Indeed, Paasche-Orlow et al, ${ }^{29}$ by studying the websites of US ethics committees, showed that the readability standards of their model information leaflets for informed consent were in most cases (in 56/61, 92\%) well beyond the target groups, the worst being six grade levels higher.

\section{INFORMED ASSENT, CONSENT AND PERMISSION}

There is an agreement already respected in most countries that, whenever possible, children should give their own opinion, in the form of written consent, for the studies they attend. However, children, especially unborn, newborn and small children, are clearly unable to consent for research by themselves. Hence, they are dependent on the decisions of their parents or of other legal guardians. Even older children, who can already express their own opinions, are naturally influenced by the people they trust the most.

Obtaining informed consent from a child, according to the available guidelines, involves necessarily the child's assent and parental (or legal guardian's) consent (proxy consent). ${ }^{6}$ In the case of very young children who are unable to assent, parental consent is of course needed in the child's best interest. ${ }^{30}$ This means that there is a consensus agreement that a "consent dyad" is required to conduct research on children. ${ }^{31}$ This is a challenge for researchers, who are responsible for ensuring informed consent. The notion of proxy consent has been dismissed by many ethicists and legalists ${ }^{32}{ }^{33}$ on the basis of the 
principle that a "true consent" cannot be given by another person. However, consensus exists that a permission is in any case necessary when studying children. Specifically, an informed permission should be obtained from a capable adult responsible for the child's participation in both therapeutic and environmental research. Then, willingness to participate (assent) should be obtained from children using an ageappropriate information process. ${ }^{26}$ The age of the candidate research participant is therefore crucial in defining the appropriate approach and tools (eg, information leaflets, abstract forms), to obtain (1) the parents' informed permission, (2) the child's assent and/or (3) informed consent from older minors. The most extreme situation is the case of research including newborns or infants whose parents (eg, the mother and/or the father) are still legal minors and not married (marriage may change legal status over age). In any case, refusal by a child to participate in a given research should always be respected and taken into account. ${ }^{6}$

If a child under the legal age to consent, which may vary between different countries, gives the assent to participate in a research, parent's informed permission should be obtained because parents know their child the best and therefore can foresee the consequences of participation for the child. There is in fact a chance that children particularly accustomed to obedience may have difficulties in expressing their negative attitude to the researchers in an unfamiliar, possibly intimidating, environment (eg, hospital, research centre). To prevent such a situation, children could give their assent to their parents, possibly at home, in a more comfortable environment. On the next day, parents would give the answers to the researchers. According to this procedure, the enrolment of a child will be possible only after the child's assent and the parent's informed permission is obtained. This rule should be applied with the exemption of the situation where parents do not give permission for their child's participation in therapeutic research. In this case, deontological rules permit that the researcher may resort to the guardianship court to authorise the child's participation in research that is either life-saving or expected to give great benefits. ${ }^{34}$

Because children cover a broad age range (ie, 0-18 years), obtaining a dyad consent for long-term studies must be viewed as a continuous process where children recruited into studies at a young age or prior to their birth (such as in studies where cord blood is collected and stored ${ }^{35}$ ) should be asked for their assent repeatedly as they grow older, until they reach the legal age for consent. It is important to realise that autonomy is not simply determined by age. Religious, cultural and ethnic differences may play an important role (table 1 gives an example). Christian anthropology, for example, recognises an embryo as a human being since conception, because of the developmental continuity, and rejects the possibility of recognising such status only at some later period of the fetal development. ${ }^{36}$ According to certain philosophical conceptions, the status of a human being is acknowledged only when a full capacity of making a free decision is reached. However, as to when a child reaches such a full capacity is not easily and objectively assessable, and it may be easier to rely on sociodemographic, age-based definitions of the developmental stages, which are, to some extent, subjective. It follows that the ability to give a truly informed consent can be expected from a child aged about 13-16 years. This argument is relevant nowadays in research on biomarkers and genetic research on children, given the growing number of biological specimens from people of various ages, stored in specifically dedicated repositories (biobanks) across the world. ${ }^{37}$

Obtaining such consent from a capable child may or may not require informed permission from parents or guardians, depending on the local legislation, culture, ethnicity, religion, and the decision of the local or national research ethics committees (RECs).

Last but not least, a free-will decision is clearly communication-dependent. Obtaining consent requires that the relevant information concerning the research (purposes, benefits, risks, right to withdraw, etc) be effectively transferred from researchers to participants so that the latter can make their decision. Unfortunately, there is evidence that this is not easily achievable, either in children or adults. ${ }^{31} 3839$ Research terminology can be a communication barrier between potential participants and researchers. In addition, environmental research is necessarily multidisciplinary, and therefore various scientific branch-specific jargons appear in research documents. Effective communication of complex concepts requires, whenever possible, the replacement of scientific and technical terms with others that are used in everyday life by the majority of the population. Descriptions of research projects can never be fully exhaustive. The Nuffield Council of Bioethics holds that, even with the best efforts, fully informed consent remains an unattainable ideal, and calls for genuine consent instead of complete consent..$^{40}$ This puts extra weight on the ethics and honesty of the scientists carrying out the research. It is their task to make every effort towards the best possible understanding between the scientists and research subjects.

\section{BIOBANKS AND CHILDREN}

For environmental molecular epidemiology, the accumulation of tissue storage in a biobank is a necessity. It is noteworthy that the definitions of a biobank vary from one source to another. Most definitions include collection of identifiable DNA samples or biological samples from where DNA can be isolated, and the possibility to connect molecular markers and lifestyle factors with health data. The Icelandic Biobank Act $^{41}$ defines a biobank as a "collection of biological samples, organic material from human beings, alive or dead, that is permanently preserved". These definitions include three points, which, if combined, create possible concern, especially relating to children: (a) the identifiability of DNA samples, (b) the possibility to connect with health data and (c) the permanently preserved specimens. Management of such combined data permanently stored, and implications in society, with the general ethical questions of how autonomy and individual rights are looked upon in relation to power and financial gain, are not simple issues. It is self-evident that individual interests and societal and financial interests do not agree in many instances. Whose interests should come first? According to the Declaration of Helsinki, it is clear that it is always the individual who should be respected above everything else. ${ }^{42}$ Children have their whole future ahead of them, but do not have an impact on the direction of development in research and on the use of samples and data. Identifiable genetic data are ethically in a special category, because it can be permanently attached to a person. Use of such data may have long-term consequences years after the data are generated, and they should thus be treated with more care than other types of health data. ${ }^{43-46}$

Samples from children will, no doubt, be a part of biobanks, especially any national biobanks. Thus, any of the issues concerning the planning, development, management and use of biobanks also concern children. In addition, as discussed above, children and unborn children are more vulnerable physically and mentally than adults on account of having less capacity to understand complex issues and long-term consequences, a capacity that is totally lacking in babies, newborn and unborn children. Furthermore, children have to live in the future we create. Children cannot themselves choose to be born, or choose their destiny when they are small. It is in the hands of their 
Table 1 Schematic representation of different approaches towards the need for informed permission, assent/consent according to different dominions

\begin{tabular}{|c|c|c|c|c|c|}
\hline \multirow[b]{3}{*}{ Dominion } & \multicolumn{5}{|c|}{ Developmental stages } \\
\hline & \multicolumn{2}{|c|}{ Prenatal } & \multicolumn{2}{|c|}{ Infancy/childhood } & \multirow{2}{*}{$\begin{array}{l}\text { Adulthood* } \\
\text { Adolescence }\end{array}$} \\
\hline & Fetus & Newborns & Infants & Childhood & \\
\hline \multirow{4}{*}{$\begin{array}{l}\text { Demography (age in years) } \\
\text { Biological relationship; possible } \\
\text { forms of permission to research } \\
\text { Philosophy }\end{array}$} & 0 & 0 & $\leqslant 2$ & $>2$ to $\leqslant 14$ & $>14$ \\
\hline & \multirow{2}{*}{\multicolumn{2}{|c|}{$\begin{array}{l}\text { Parents; informed permission† } \\
\text { Fetus; implicit assent }\end{array}$}} & Parents; & & Parents; informed permission† \\
\hline & & & Infant; in & Child; assent & Child; assent or consent \\
\hline & \multicolumn{4}{|c|}{ Status as a human being recognised only when the full capability of free decision is reached } & $\begin{array}{l}\text { Full capability of free decision } \\
\text { (age, maturity) }\end{array}$ \\
\hline Religion & \multirow{2}{*}{\multicolumn{4}{|c|}{$\begin{array}{l}\text { Status as a human being recognised from conception onwards } \\
\text { Ethical regulators: decisions apply to all ages }\end{array}$}} & \\
\hline Ethics & & & & & \\
\hline Law & \multicolumn{5}{|c|}{ Status as a human and requirement/possibility for individual consent depending on national legislations } \\
\hline
\end{tabular}

parents, and even more in the hands of society, through the legislation defining, for example, the value of life. Issues of suffering and, by contrast, the financial costs of screening and care, are often discussed in connection with serious hereditary conditions. What are discussed much less are the ethical costs and what kind of society is preferable. In addition to physical vulnerability, children are at the mercy of adults regarding their mental integrity. Children largely adopt the values and ways of the society they live in, especially through parents, school and the media. It is, of course, not so much the question of what values are discussed and taught than the question of what values are actually practised. Indeed, children can be considered as "autonomous subjects" at various ages according to the "traditions" of the "moral community" they live in. ${ }^{47}{ }^{48}$ The development of children varies a lot, but all small children have less capacity to handle difficult issues. It is partly a question of intelligence, but life experience should not be overlooked. Even in early adulthood, people are not fully developed in their inner values and needs. The minds of young children are easily adjusted to the will of respected adults. When fully grown and psychologically mature, people may even represent contrasting values compared to their early age. This may change their earlier views on belonging to a biobank and on use of their samples. Because there are no experiences on long-term storage and use of biobanks at this point, it is difficult even for adults to consider the implications and what may be expected.

In DNA studies, there is always the possibility of incidental related findings, not sought by the studies. Illes and coworkers ${ }^{49}$ propose a national database for incidental findings, including false positives in NMR imaging of normal volunteers, to gain more insight into their long-term effects. Their proposal includes the collection of the following details of the incidental findings: circumstances of detection, how the finding was handled, to whom it was reported, the manner in which it was reported, how the finding was followed up and the outcome for the individual. Such a procedure would also be very important in connection with any data collected as a consequence of national DNA banks. With children, the follow-up will be long enough to get meaningful data of lifetime consequences.

\section{ROLE OF RECS IN STUDIES ON CHILDREN}

There is a general agreement (according to the Declaration of Helsinki) ${ }^{5}$ about the need for approval from an ethics committee for any biomedical research in children as well as in adults. The evaluation by an independent ethics committee is required by law in many European countries (eg, Denmark, Finland, Italy), and by all respectable biomedical journals. ${ }^{50}$ In addition, there is a demand for appropriate procedures for stringent follow-up, aimed at assuring the integrity of research and researchers according to the study protocol and across the conduct of the study.

The composition of committees varies considerably across Europe..$^{51}$ In some cases-for example, in UK-there is variety even between the committees within one country. This degree of variation in composition (both in the number of members and in their expertise) suggests that there is limited uniformity in the purpose of RECs and their decision-making across Europe. In most countries RECs assess the scientific validity, the value of the proposed research and the privacy issue. Because the design of the study is an important aspect of any research, the committee should be properly equipped to judge this part of the written protocol. Informed medical judgements are also needed in order to make a reasonable assessment of the risk/benefit ratio for the research. These are matters on which medical experts, rather than layman, are properly qualified to judge. To make a sound scientific judgement, epidemiologists, biostatisticians and pharmacologists should be represented in addition to physicians as medical experts. These professions can provide additional expertise in judging the quality of design and risks for the research participants. For studies including children, the expertise of paediatricians should also be included. Some other disciplines can also be very helpful. For instance, in Poland, a lawyer and a priest are included in the committees in addition to doctors, pharmacists and ethicists.

\section{CONCLUSIONS AND RECOMMENDATIONS}

Ethical issues concerning children and environmental health are attracting increasing attention. ${ }^{52} 53$ In any studies on children and minorities, it is important to consider how the ethical issues should be dealt with, and to document the practices. There is a need for harmonisation within Europe, especially because, in addition to clinical trials on drugs, large multinational studies are becoming more common even in the environmental health field. Harmonisation is needed in the practices of REC as well as in the handling of the informed consent issue.

For environmental health studies, biobanks are regarded as a necessity. Large-scale biobanks will collect and store samples and also data permanently from children. Because DNA data will be linked with health data, it is not advisable to base the management of such biobanks on private ownership. Concerning biobanks and children, any such projects should include a follow-up of at least one of the following items: (1) the opinions of donors approached as children or through their parents after they have grown up, with the possibility to withdraw from the biobank; (2) the handling of incidental findings, especially false positives with putative psychological implications; and (3) how the financial aspects of the biobank have been handled. The most 
important recommendation is to consider, in connection with any studies on children, how to concurrently improve the life and health of the participating children.

According to the workshops held within the CHILDRENGENONETWORK in 2003 and 2005, and the increasing number of activities following the European Commissions action plan on Environment and Health, most points of the critical review of the guidelines made by the Ethics Working Group of the Confederation of European Specialists in Paediatrics ${ }^{54} 55$ and guidelines by ethics groups considering children $^{56}{ }^{57}$ are directly applicable to environmental research. In addition to the general requirements for good research on humans (necessity, scientifically good planning with as few research subjects as possible, potential benefit overriding potential risks, approval of an independent REC) and the vulnerability of children (only research benefiting directly children or the group they represent), the following key points must be considered when planning research on children ${ }^{58}$ :

1. children should always be respected as persons;

2. an assent/consent from the child and parental permission (ie, consent dyad) should be sought whenever possible, by using appropriate tools;

3. an abbreviated description of the research for getting research participants' informed permission/assent/consent must be written in understandable language according to the age of the target group(s); (In studies involving children at least two information sheets are required: one for children and one for their parents.)

4. enough time should be given for parents and children to discuss the research and consider their participation in a friendly environment;

5. refusal to participate by a child should be respected;

6. the presence of parents should be ensured in the interventions if practically possible, for the child's comfort and to ensure that the rights of the child are looked after;

7. special attention has to be paid to the most vulnerable children (institutionalised, homeless, impoverished and sick children);

8. children from different countries or belonging to different ethnic, social or religious groups should be treated with the same respect;

9. follow-up tools must be considered by researchers to monitor long-term effects in study participants, considering incidental findings;

10. for the evaluation of studies including children, a paediatrician should always be included in the REC.

\section{ACKNOWLEDGEMENTS}

This work was supported by the European Commission fifth FP CHILDRENGENONETWORK-QLK4-CT-2002-02198 and sixth FP NewGeneris-FOOD-CT-2005-016320.

\section{Authors' affiliations \\ D F Merlo, Epidemiology and Biostatistics, Istituto Nazionale per la Ricerca sul Cancro, Genova, Italy \\ L E Knudsen, Environmental Health Institute of Public Health, University of Copenhagen, Copenhagen, Denmark \\ K Matusiewicz, Department of Psychology, Medical University of Silesia, Katowice, Poland \\ L Niebrój, Department of Philosophy and Ethics, Medical University of Silesia, Katowice, Poland \\ K H Vähäkangas, Department of Pharmacology and Toxicology, University} of Kuopio, Kuopio, Finland

Competing interests: None.

\section{REFERENCES}

1 The Nuremberg Code. "Trials of War Criminals Before the Nuremberg Military Tribunals Under Control. Council Law No. 10", Vol 2, Nuremberg, October 1946-April 1949. Washington, DC: US Government Printing Office, 1949.

2 The National Commission for the Protection of Human Subjects of Biomedical and Behavioural Research. The Belmont Report: ethical principles and guidelines for the protection of human subjects of research, OPRR Reports, 1979.

3 Royal College of Physicians. Guidelines on the practice of ethics committees in medical research involving human subjects, 2nd edn. London: Royal College of Physicians, 1990.

4 International Conference on Harmonisation. Good clinical practice: consolidated guideline, May 1997. In: Nimmo WS, ed. Joint consensus conference on misconduct in biomedical research. Proc $R$ Coll Physicians Edinb 2000;30(Suppl 1):1-26.

5 World Medical Association Declaration of Helsinki. Ethical Principles for Medical Research Involving Human Subjects: 52nd WMA General Assembly, WMA, Edinburgh, Scotland, October 2000.http://www.wma.net (accessed 20 Mar 2007).

6 CIOMS. International ethical guidelines for biomedical research involving human subjects. Geneva: CIOMS, 2002

7 British Pediatric Association. Guidelines for the ethical conduct of medical research involving children. London: BPA, 1992.

8 Beauchamp TL, Childress JF. Principles of biomedical ethics, 5th edn., New York: Oxford University Press 2001.

9 Baruch A. Brody, Making meaningful consent meaningful. IRB Ethics Hum Res 2001;23:1-5.

10 The Children's Health Act of 2000; Public Law 106-310. Weekly compilation of Presidential documents, Presidential Statements. Vol 36. 17 Oct. 2000.

11 National Academy of Sciences (NAS). Pesticides in the diets of infants and children. Washington, DC: National Academy Press, 1993.

12 Neri M, Bonassi S, Ugolini D, et al. Children's exposure to environmental pollutants and biomarkers of genetic damage. I. Overview and critical issues. Mutat Res 2006;612:14-39.

13 Anderson LM, Diwan BA, Fear NT, et al. Critical windows of exposure for children's health: cancer in human epidemiological studies and neoplasms in experimental animal models. Environ Health Perspect 2001;109:573-94.

14 Wild CP, Kleinjans J. Children and increased susceptibility to environmental carcinogenesis: evidence or empathy? Cancer Epidemiol Biomarkers Prev 2003;12:1384-9

15 Clark PA. AIDS research in developing countries: do the ends justify the means? Med Sci Monit 2002;8:5-16.

16 Acredolo L, Goodwyn S. Symbolic gesturing in normal infants. Child Dev 1988;59:450-66.

17 Astington J. The child's discovery of the mind. Cambridge, MA: Harvard University Press, 1993.

18 Bretherton I, Beeghly $M$. Talking about internal states: the acquisition of an explicit theory of mind. Dev Psychol 1982;18:906-21.

19 Belmont JM. Cognitive strategies and strategic learning. The socio-instructional approach. Am Psychol 1989;44:142-8.

20 Mouonoud P. Similarities between developmental sequences at different age periods. In: Levin I, eds. Stage and structure. Norwood, New Jersey: Albex, 1986:40-58.

21 Jackson S, Rodriguez-Tome HR. Adolescence and its social world. Hove: Erlbaum, 1993.

22 Lazarus RS, Folkman S. Transactional theory research on emotion and coping Eur J Pers 1987;1:141-69.

23 Lazarus RS. Emotion and adaptation. London: Oxford University Press, 1991.

24 Folkman S. Personal control and stress and coping processes: a theoretical analysis. J Pers Soc Psychol 1984;46:839-52.

25 Folkman S, Lazarus RS. If it changes it must be a process: study of emotion and coping during three stages of a college examination. J Pers Soc Psychol 1985;48:150-70

26 Lazarus RS. Coping theory and research, past, present and future. Psychosom Med 1993;55:234-47.

27 Folkman S. Making the case for coping. In: Carpenter BN, eds. Personal coping:theory, research, and application. Westport, CT: Praeger Publishers, 1992:31-46.

28 Wolthers $\mathrm{O}$. Age and gender related differences in children's evaluation of procedures experienced during participation in clinical research. Eur J Pediatr 2005; 164:50-1.

29 Paasche-Orlow MK, Taylor HA, Brancati FL. Readability standards or informed consent forms as compared with actual readability. N Engl J Med 2003;348:721-6.

30 Pellegrino ED. The anatomy of clinical-ethical judgments in perinatology and neonatology: a substantive and procedural framework, Semin Perinatol 1987; 11:202-9.

31 Bergler JH, Pennington C, Metcalfe $M$, et al. Informed consent: how much does the patients understand? Clin Pharmacol Therap 1980;27:435-40.

32 Simar R, Johnson VA. Pediatric informed consent. Challenges for investigators. Appl Clin Trial 2002; 7:3-10.

33 Committee on Bioethics, American Academy of Pediatrics. Informed consent, parental permission, and assent in pediatric practice. Pediatrics 1995;95:314-17.

34 Kodeks Etyki Lekarskiej. Warszawa: Wyd. NIL, 2004. http://www.nil.org.pl (accessed 20 Mar 2007).

35 Goodenough T, Williamson E, Kent J, et al. Ethical protection in epidemiological genetics. Participant's perspectives. Including children in the debate. European Meeting on ethical aspects in studies on placental tissue and during pregnancy 
and childhood. Copenhagen, 5-7 December 2003. Available at CHILDRENGENONETWORK Home Page, http://www.pubhealth.ku.dk/cgn/ (accessed 20 Mar 2007).

36 Biesaga T. Antropologiczny status embrionu ludzkiego. In: Biesaga T. (ed) Podstawy I zastosowania bioetyki. Wydawnictwo Naukowe Papieskiej Akademili Teologicznej, Kraków, 2001:101-12.

37 Cambon-Thomsen A. Assessing the impacts of biobanks. Nat Genet 2003;34:25-6.

38 Byrne DJ, Napier A, Cuschieri A. How informed is signed consent? BMJ 1988:296:839-84.

39 Lynoe N, Sandlund M, Dahlqvist, et al. Informed consent: study of quality of information given to participants in a clinical trial. BMJ 1991;303:610-13.

40 The Nuffield Council on Bioethics. The ethics of research related to healthcare in developing countries. http://www.nuffieldbioethics.org (accessed on 20 Mar 2007).

41 Arnason V. Coding and consent. Moral challenges of the database project in Iceland. J Bioethics 2004;18:27-49.

42 Vähäkangas $\mathrm{K}$. Ethical aspects of molecular epidemiology and cancer. Carcinogenesis 2004;4:465-71.

43 United Nations Educational, Scientific and Cultural Organization (UNESCO). International declaration on human genetic data. Adopted on 16 Oct 2003 by the 32nd session of the General Conference of UNESCO. hitp:// portal.unesco.org (accessed 20 Mar 2007).

44 Clayton EW. Ethical, legal and social implications of genomic medicine. New Engl J Med 2003;349:562-9.

45 Vähäkangas KH. Ethical implications of genetic analysis of individual susceptibility to diseases. Mutat Res 2001;482:105-10.
46 Knudsen LE. Global gene mining and the pharmaceutical industry. Toxicol Appl Pharmacol 2005;207:S679-83.

47 Maclntyre A. After virtue. A study in moral theory, 2nd edn. Notre Dame: University of Notre Dame Press, 2003.

48 Maclntyre A. Three rival version of moral enquiry, Encyclopaedia, genealogy, and tradition. Notre Dame: University of Notre Dame Press, 1990.

49 Illes J, Desmond JE, Huang LF, et al. Ethical and practical considerations in managing incidental findings in functional magnetic resonance imaging. Brain Cogn 2002:50:358-65.

50 COPE Committee on Publication Ethics. Guidelines on good publication practice, http://www.publicationethics.org.uk (accessed 20 Mar 2007).

51 Beyleveld D, Townend D, Wright J, eds. Research Ethics Committees, Dato protection and medical research in European countries. Hampshire, UK: Ashgate Publishing Limited, 2005.

52 Van Larebeke NA, Birnbaum LS, Boogaerts MA, et al. Unrecognized or potential risk factors for childhood cancer. Int J Occup Environ Health 2005;11:199-201.

53 Gilbert SG. Ethical. Legal and social issues: our children's future, NeuroToxicology 2005;26:521-30.

54 Gill B. Informed consent for neonatal research. Curr Pediatr 2002;12:503-7.

55 Gill B. Guidelines for informed consent in biomedical research involving paediatric populations as research participants. Eur J Pediatr 2003;162:455-8.

56 Saver PJ. Research in children. A report of the ethics working group of the CESP. Eur Jf Pediatr 2002;161:1-5.

57 Edwards SD, McNamee MJ. Ethical concerns regarding guidelines for the conducy of clinical research on children. J Med Ethics 2005;31:351-4.

58 Grodin MA, Glanz LH, eds. Children as research subjects. Science, ethics and law. New York: Oxford University Press, 1994.

\section{Access a vast information database with Toll-Free linking}

"Toll-free" linking gives you immediate access to the full text of many of the cited articles in a paper's reference list-FOR FREE. With the support of HighWire's vast journal catalogue, a huge reference library is now open to you. If HighWire hosts the journal, you can view the full text of the referenced article, completely free of charge by following the Free Full Text links in the references. 